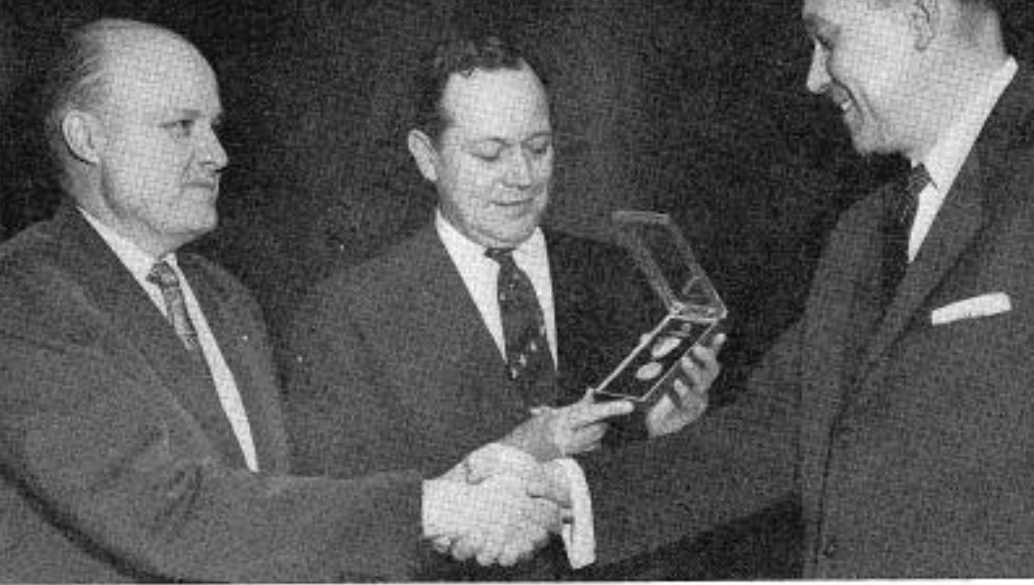

AWARD WINNER MILES (left) receives congratulations from Halbert B. Miller, Manufacturing Services vice president, while C. Willard Bryant, Materials Service manager, holds medal given Miles by U.S.Navy.

\section{WE SALUTE}

Lawrenee D. Miles, manager of Value Analysis Service, Schenectady, on receiving the highest civilian honor the Navy can bestow: the Distinguished Public Service Award. His case is an outstanding example of how General Electric and its employees have cooperated with the government to help the nation get more value for its defense dollar. This chain of events led to the award: Several years ago, Admiral Wilson D. Leggett, then Chief of the Navy's Bureau of Ships, accompanied by Vice President Glenn B. Warren, visited Turbine Division plants. When the Admiral expressed concern over rising costs of all Naval equipment, Mr. Warren cited General Electric's Value Analysis program, whose purpose is to provide equivalent performance of equipment and material at vastly lower cost. Admiral Leggett showed interest, and Value Analysis expert Miles (photo above) was asked to make a formal presentation on the subject to the Navy. Subsequently, he helped establish the Navy's Value Engineering Office, based on the fundamentals and techniques of Gen. eral Electric's operation. The result, according to Mr. Miles' citation: "Sizable dollar savings for the Navy."

Harold F. Smiday, vice president, Management Consultation Services, on his recent election as a Fellow in the Academy of Management - the highest pos. sible rank in the Academy, and another of the many honors he has received (The Monogram, Nov. 1957 , p. 20). The election was made in recognition of $\mathrm{Mr}$. Smiddy's substantial contributions to the field of management, evidenced by his articles in leading management journals.

Dutstandiug Citizems - Anniston's Wilfred L. Gorrell, Wayneshoro's Henry W. Tulloch, and Tell City's William J. Mangum - for their vigorous participation in local community affairs in 1957. Wilfred Gorrell, 


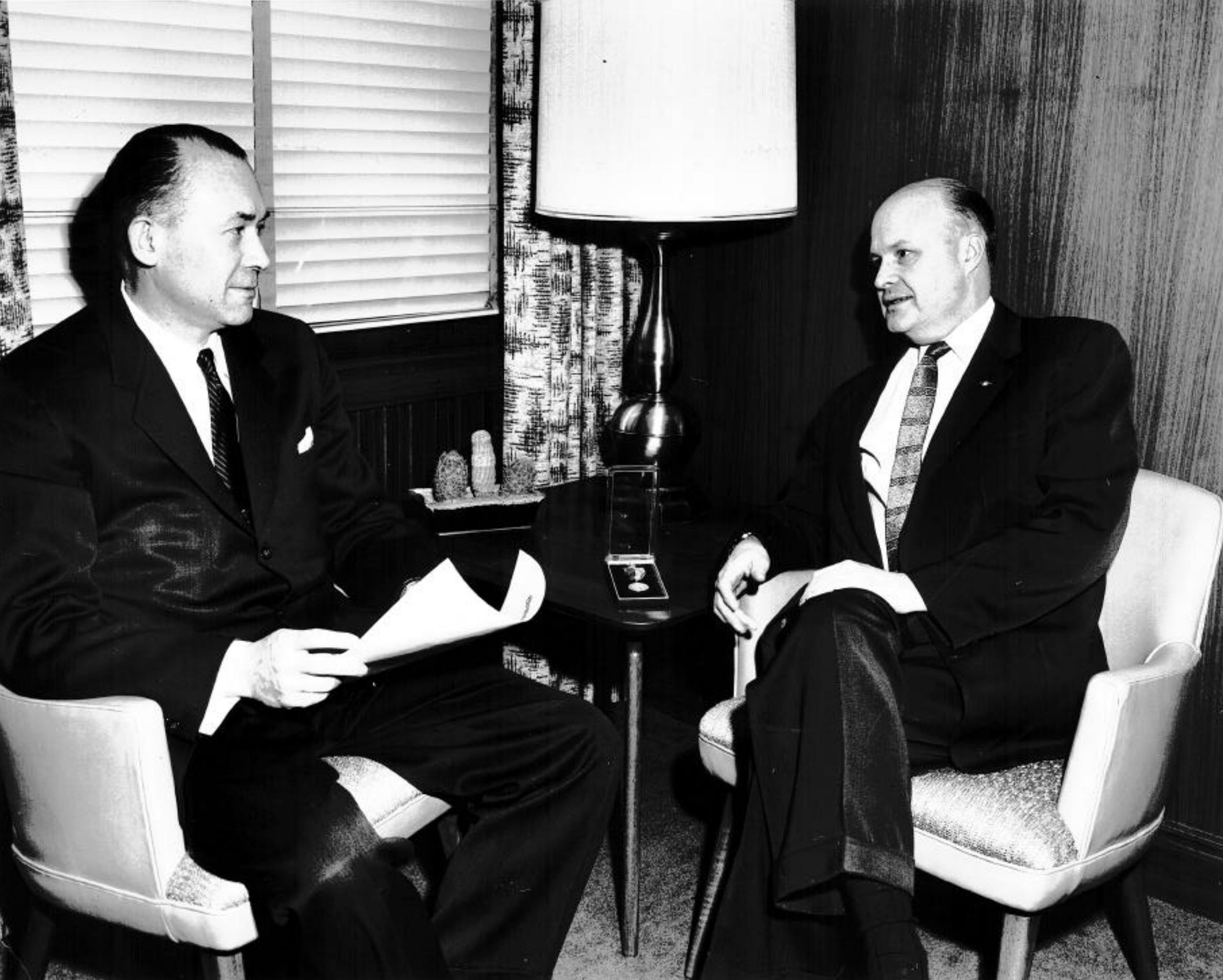



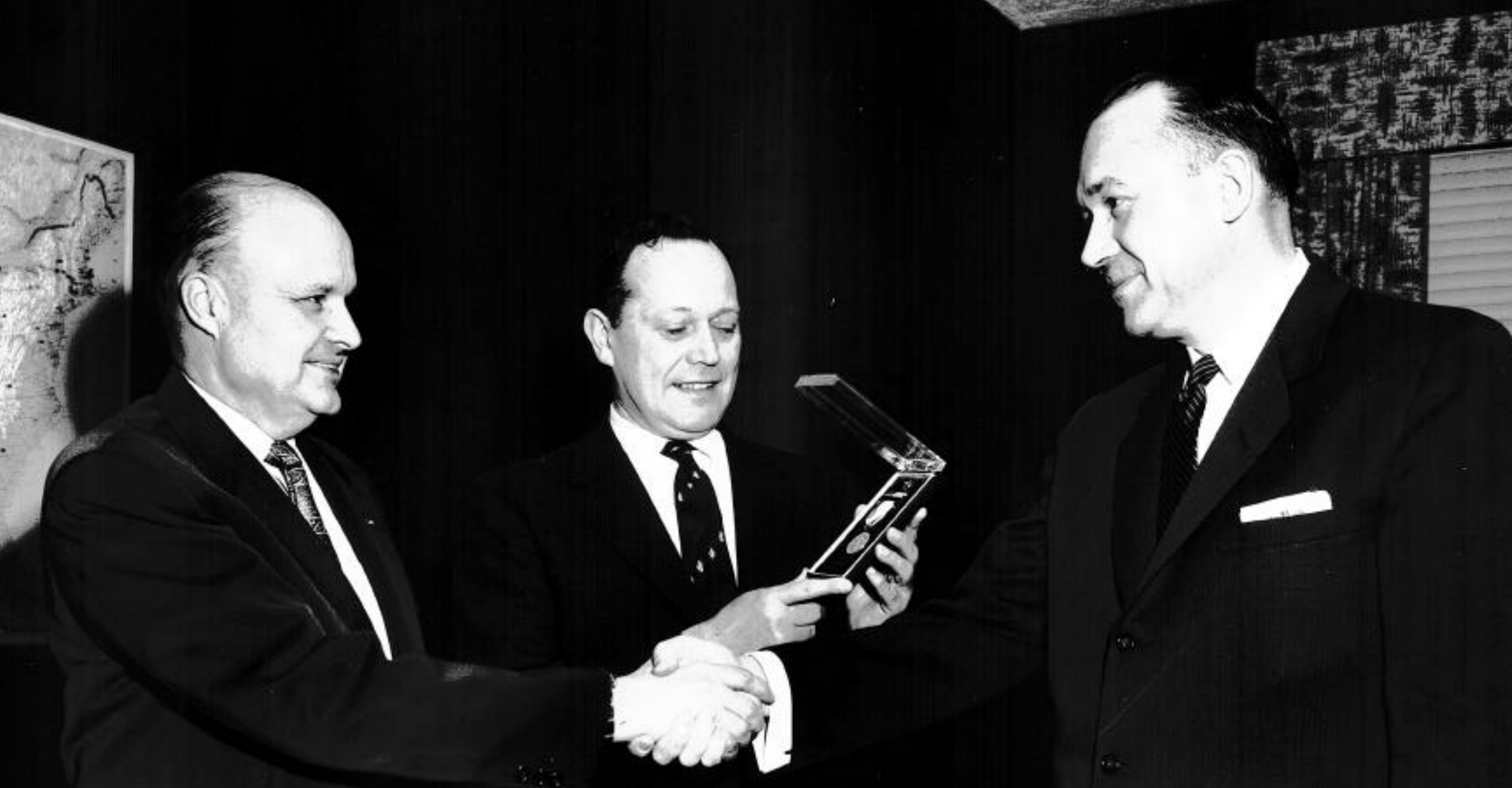

y

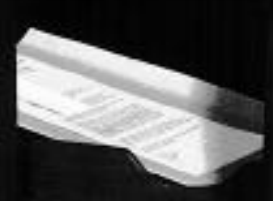

1

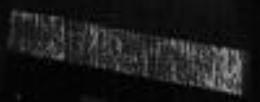




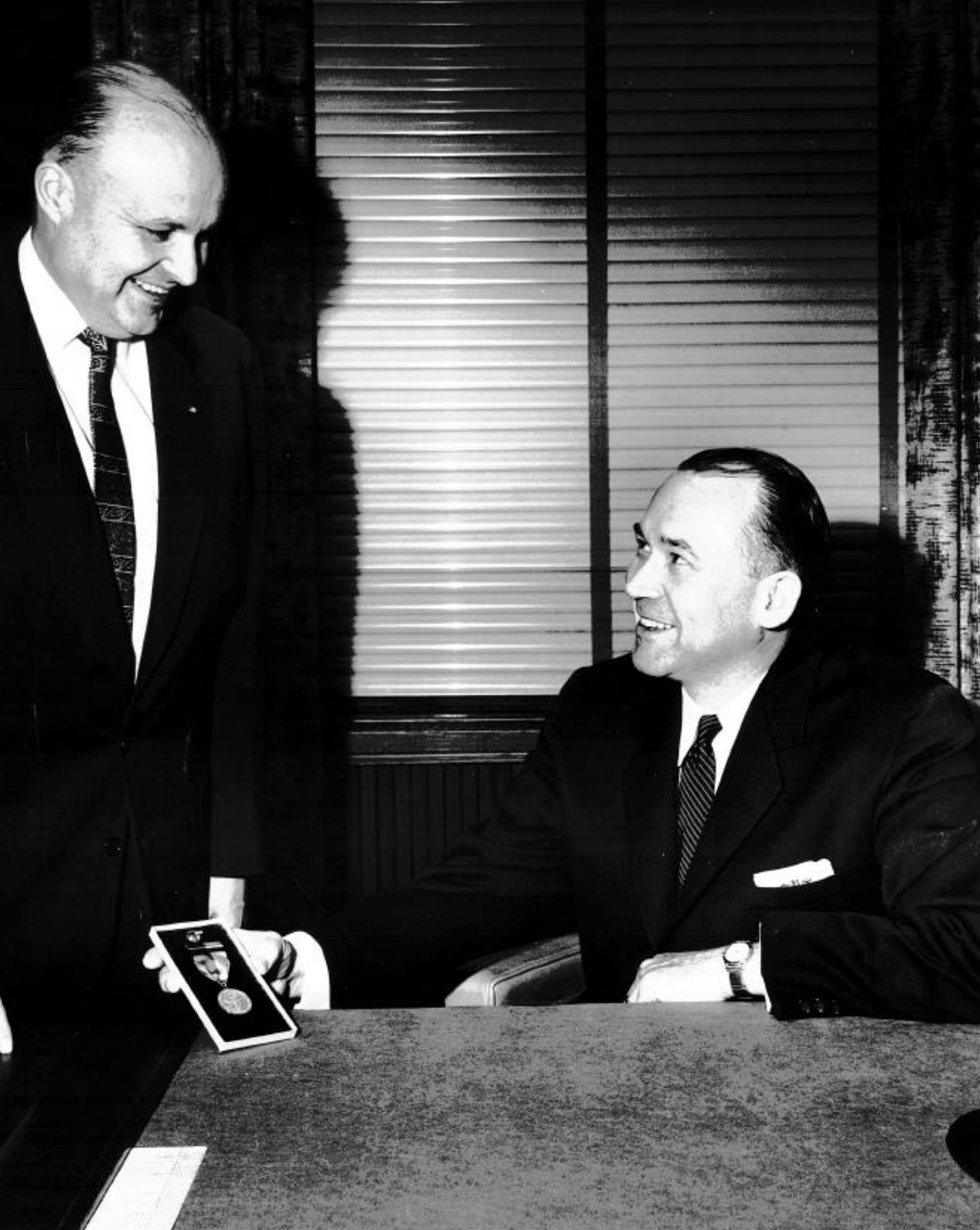




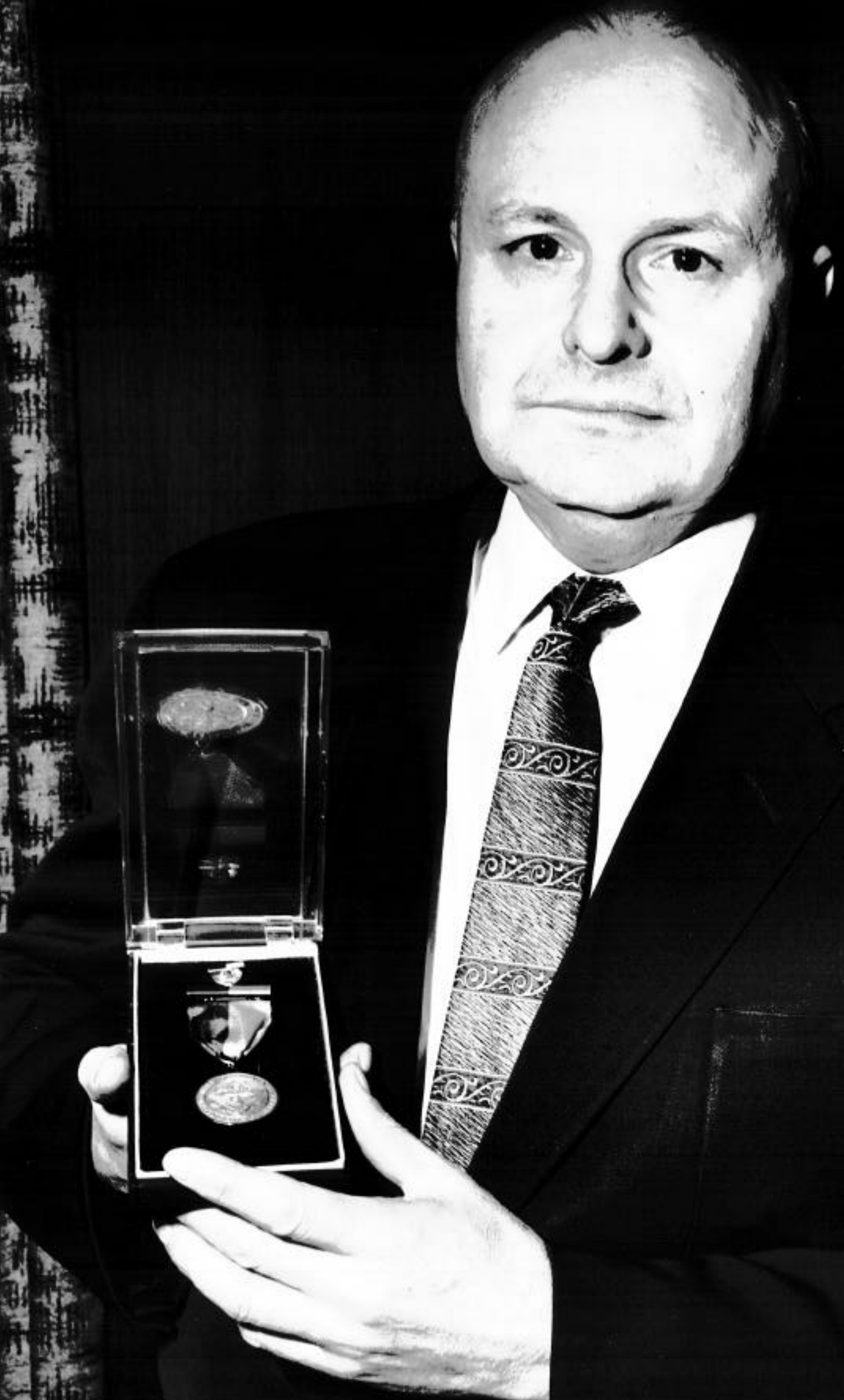




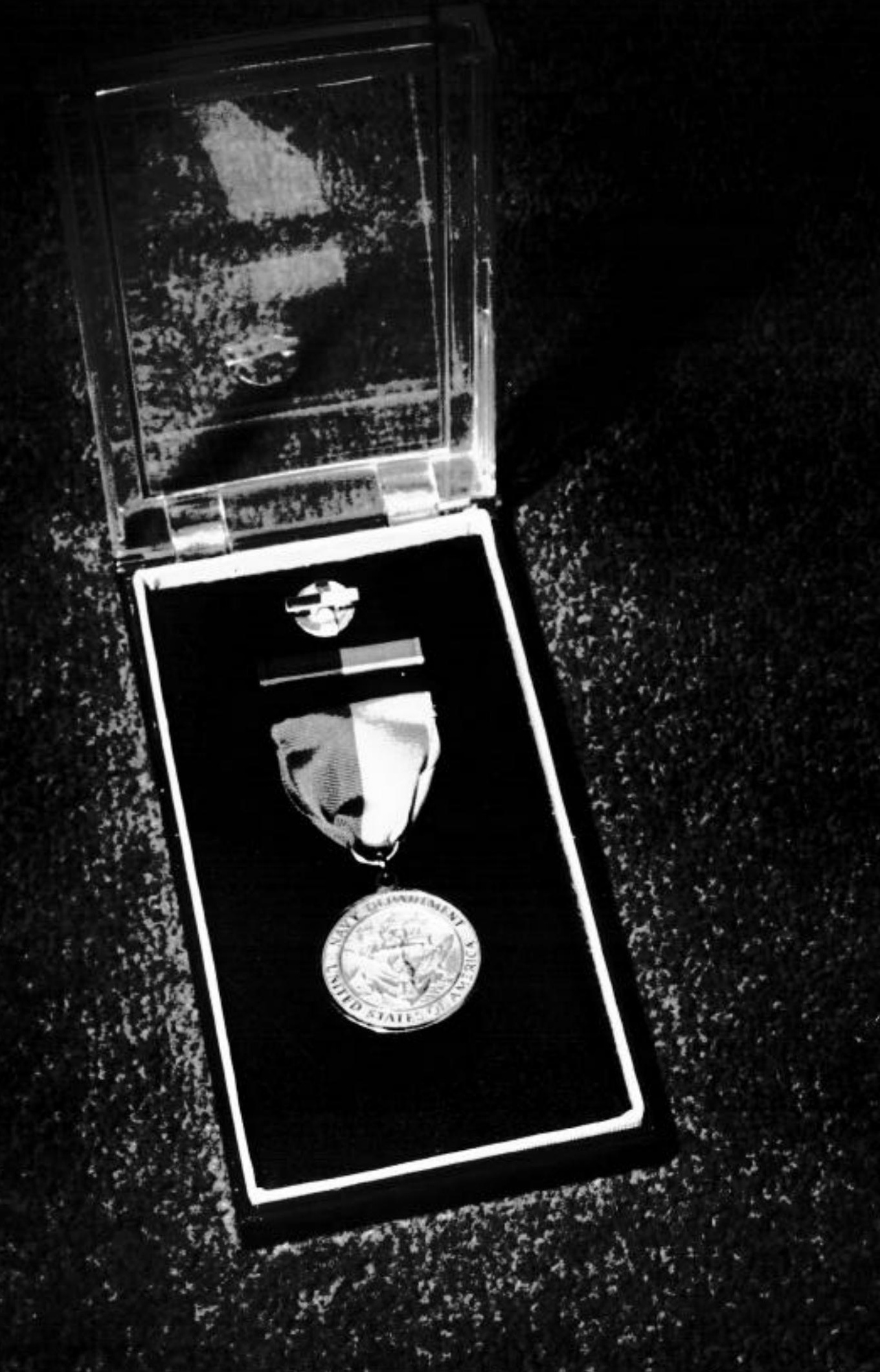




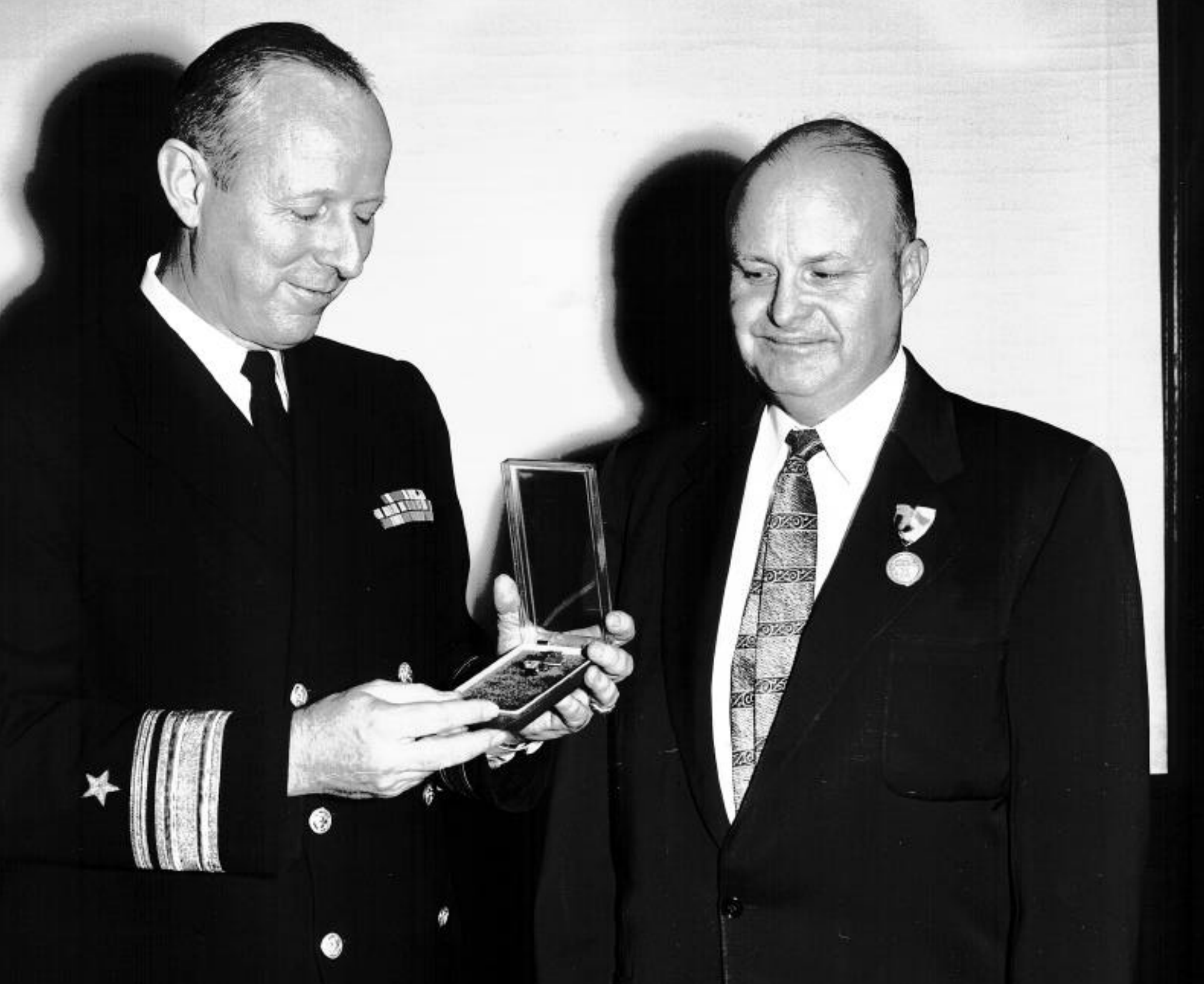




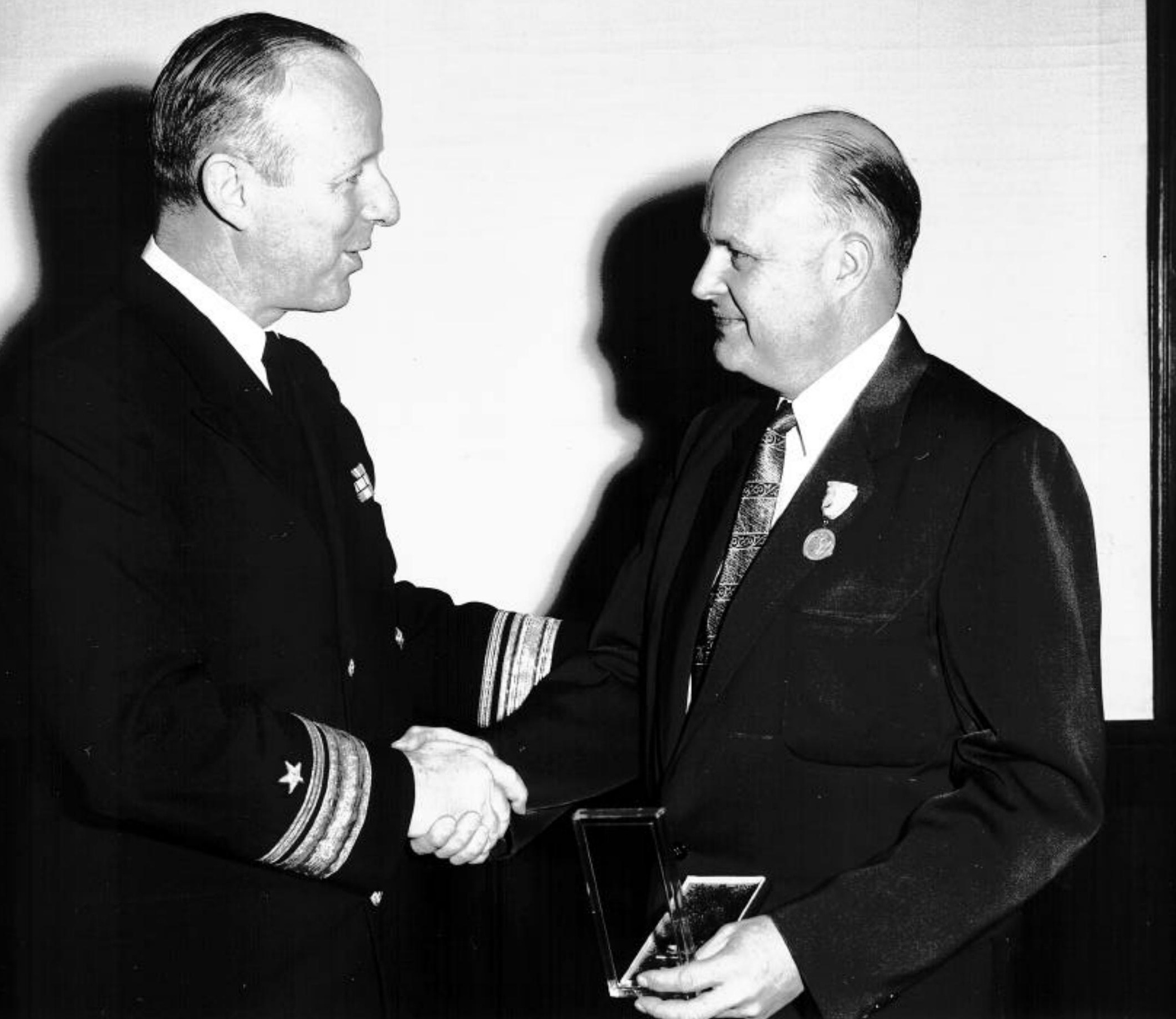




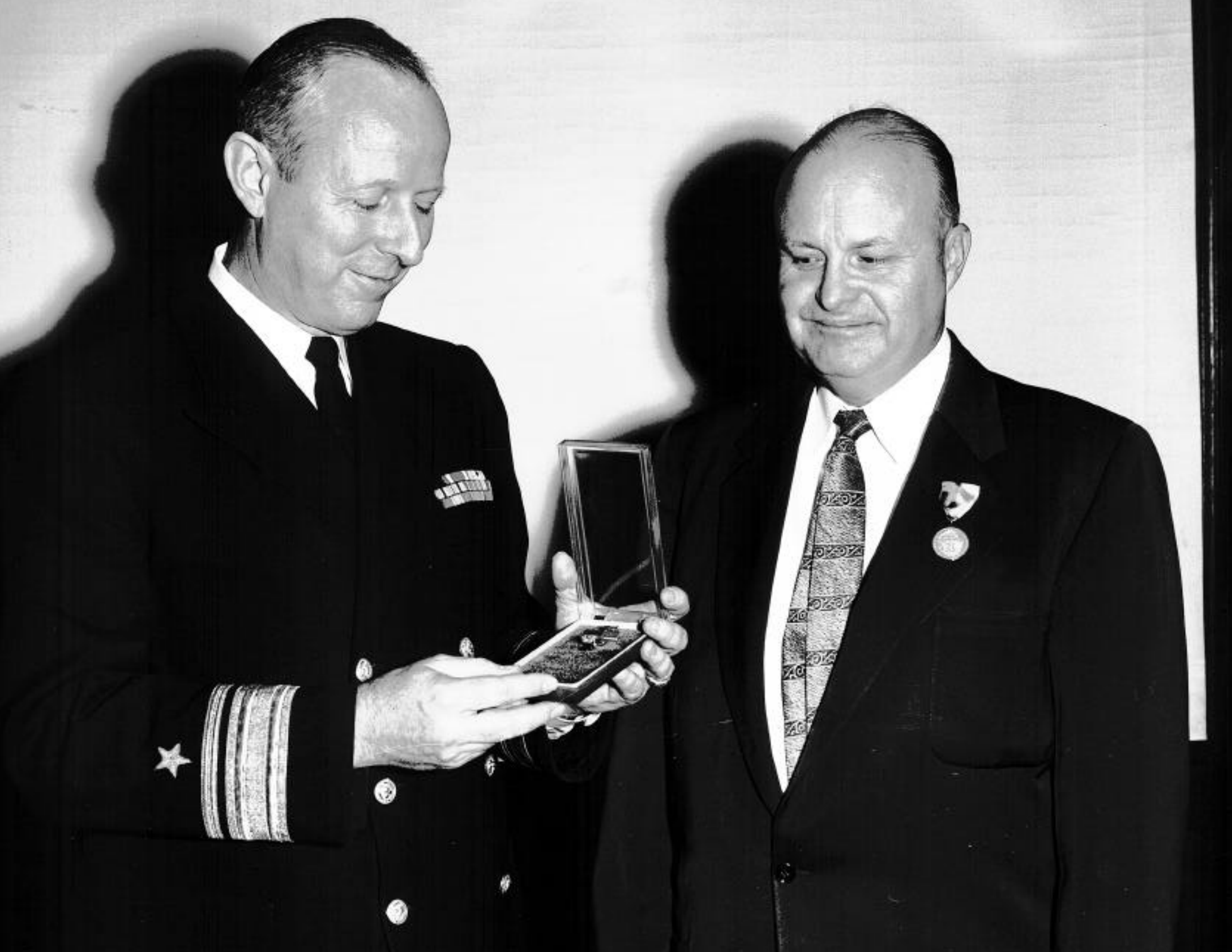




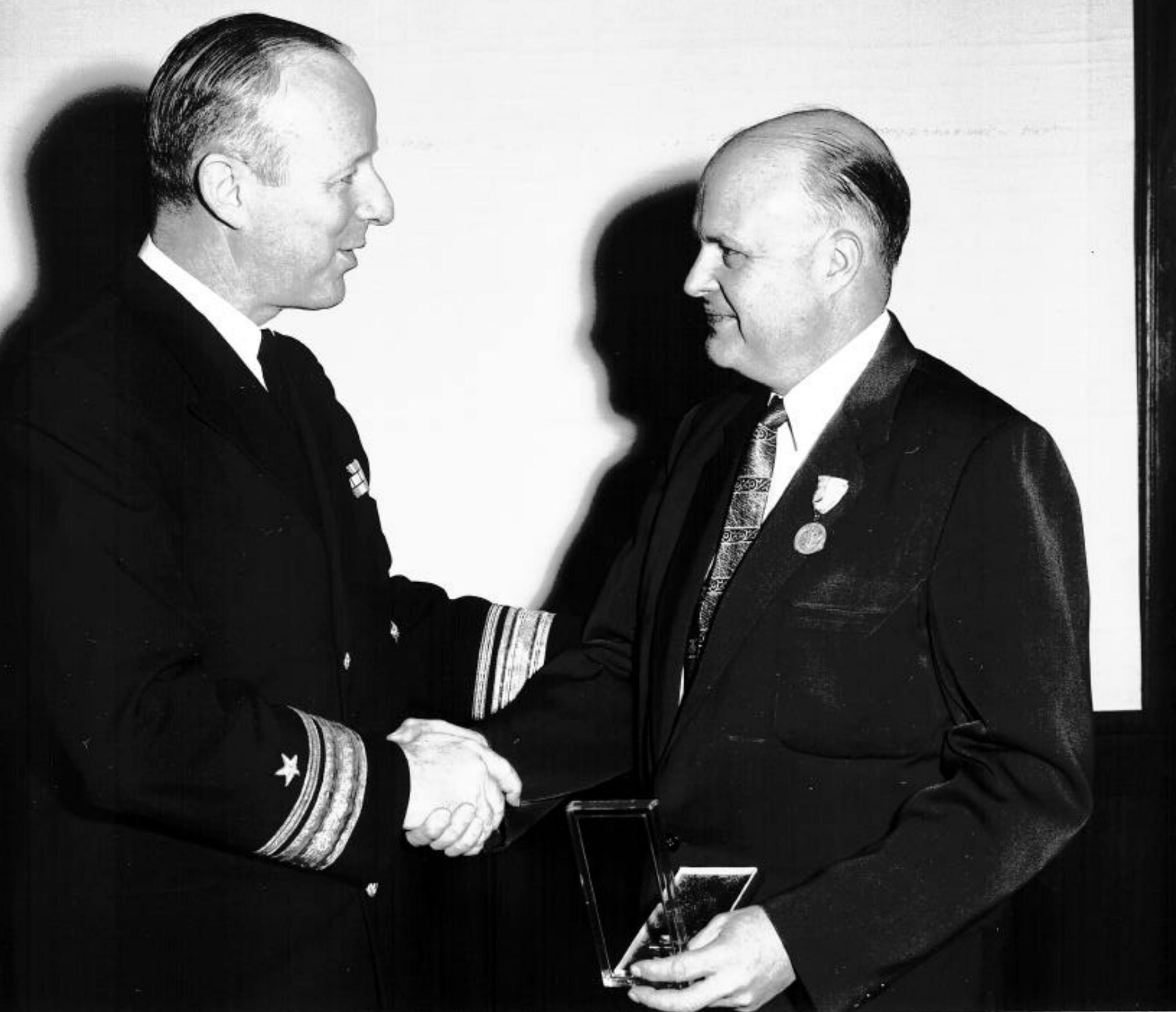




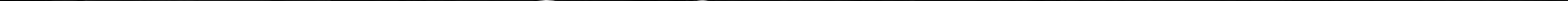

